\title{
ATIVIDADES DE ENSINO EM ESPAÇOS NÃO FORMAIS AMAZÔNICOS: UM RELATO DE EXPERIÊNCIA INTEGRANDO CONHECIMENTOS BOTÂNICOS E AMBIENTAIS
}

\author{
Terezinha de Jesus Vilas Boas Barbosa ${ }^{1}$ \\ Lucilene da Silva Paes² \\ Jean Dalmo de Oliveira Marques ${ }^{3}$ \\ Marciléa Silva de Freitas 4 \\ Lourian Almeida Tavares ${ }^{5}$
}

\begin{abstract}
Resumo: $O$ ensino de botânica constitui uma ferramenta fundamental no sentido de fortalecer a conscientização do uso, manejo e conservação ambiental. O desenvolvimento de atividades de ensino nos Espaços Não Formais (ENFs) amazônicos pode propiciar processos de aprendizado significativos para o ensino de botânica valorizando a biodiversidade de plantas regionais e consequentemente contribuindo para a formação de uma concepção ambiental. Desta forma o presente trabalho teve como objetivo relatar uma experiência da autora na construção de sua dissertação indicando como os EFNs amazônicos podem ser utilizados no processo de ensino disseminando conhecimentos quanto aos componentes da flora e sua importância para o meio ambiente. O estudo foi realizado no Instituto Federal de Educação Ciência e Tecnologia do Amazonas/IFAM por meio de entrevistas com alunos e professores do curso de Licenciatura em Ciências Biológicas. Trata-se de uma pesquisa de cunho qualitativo visando aprimoramento das ações coletivas no campo pedagógico, subsidiando os aspectos inovadores da autorreflexão. O diagnóstico permitiu observar qual a concepção que os alunos têm quanto a temática no início do curso de e como é trabalhado o tema em questão ao longo dos períodos. Posteriormente, realizou-se uma intervenção através de atividade desenvolvida nos ENFs. A pesquisa indicou que os conhecimentos botânicos podem ter melhor desenvolvimento e compreensão quando desenvolvidos em ENFs, desmistificando a botânica como de difícil compreensão, além de despertar a concepção ambiental como instrumento para a manutenção do ambiente equilibrado.
\end{abstract}

Palavras-chave: Botânica; Concepção Ambiental; Espaço não Formal.

\footnotetext{
1 IFAM - Instituto Federal de Educação, Ciência e Tecnologia do Amazonas: tjvbb2050@gmail.com

2 IFAM - Instituto Federal de Educação, Ciência e Tecnologia do Amazonas: lusilvapaes@gmail.com

${ }^{3}$ IFAM - Instituto Federal de Educação, Ciência e Tecnologia do Amazonas: jdomarques@hotmail.com

4 IFAM - Instituto Federal de Educação, Ciência e Tecnologia do Amazonas: msf@hotmail.com

5 IFAM - Instituto Federal de Educação, Ciência e Tecnologia do Amazonas: lata@hotmail.com

Revbea, São Paulo, V. 11, № 4: 174-183, 2016.
} 


\section{Introdução}

A Amazônia é conhecida como bioma com megadiversidade, pois possui altos índices de riqueza natural. A floresta tem papel fundamental no funcionamento dos ecossistemas nos quais, se desenvolvem processos essenciais à vida humana, na regulação do ciclo da água, na proteção contra erosões, manutenção da qualidade do solo, polinização, reciclagem de dejetos e como barreiras contra as catástrofes naturais (SECCO e SANTOS, 2008). Diante dessa riqueza Araújo et al. (2011) afirmam que a Região Amazônica dispõe de recursos naturais que podem funcionar como um laboratório vivo, um celeiro para o desenvolvimento de processos eficazes de aprendizagem para o Ensino de Ciências.

Apesar da existência de uma grande diversidade nos diferentes ecossistemas, a realidade do ensino de botânica nas escolas é marcada pelo desinteresse e desmotivação. Kinoshita et al., (2006) afirmam que a forma como o ensino de Botânica é difundido ainda é muito teórico e desestimulante para alunos tornando-o subvalorizado dentro do Ensino de Ciências e Biologia. Uma das prováveis explicações para isto é a estranha terminologia usada para denominar formas e padrões tão fortemente impregnados de helenismo e latinismo e por não possuírem, ao contrário dos animais, partes exatamente correspondestes as nossas (GONÇALVES; LORENZI, 2008).

De uma forma geral, Pinto et al. (2009) acrescentam que os processos metodológicos tradicionais utilizados no ensino de Ciências e Biologia têm recebido várias críticas, pois existe a falta de um vínculo entre o conteúdo ensinado e a realidade dos alunos. Para Araújo e Silva (2013) a educação nos tempos atuais não pode ficar restrita apenas ao contexto da escola.

Os educadores de Ciências e Biologia podem utilizar os ENFs como alternativas para processos de ensino e aprendizagem conciliando conceitos e práticas visíveis nos ambientes naturais. Principalmente na região amazônica que constituem um dos cenários mais ricos em recursos naturais.

Atividades nos ENFs podem promover a sensibilização quanto aos problemas socioambientais e contribuir para uma educação que formará indivíduos sensíveis e solidários, cidadãos conscientes dos processos e regularidades de mundo e da vida (BRASIL, 1999). A perspectiva do Ensino de Ciências para o contexto amazônico viabiliza o alcance do objetivo dos PCNs de "valorizar a vida em sua diversidade e a preservação dos ambientes". A Educação Ambiental deve favorecer os processos que permitam que os indivíduos ampliem a sua percepção e internalizem, conscientemente, a necessidade de mudanças, intervindo diretamente no contexto social, o que confere a qualidade de atores políticos (DIAS, 2004).

A formação do cidadão crítico é um dos elementos essenciais para as mudanças significativas de valores e de conscientização da realidade, tornando-o capaz de compreender e exigir seus direitos ambientais, estando 
disposto a exercer sua responsabilidade e poder político necessários à emergência de mudanças pessoais e coletivas. Esses aspectos contribuem para o seu autoconhecimento como cidadão ambiental. "A cidadania ambiental compreende as obrigações éticas que nos vinculam tanto à sociedade como aos recursos naturais do planeta de acordo com o nosso papel social e na perspectiva do desenvolvimento sustentável' (GUTIÉRREZ, 2008, p. 14).

O ensino de Botânica constitui uma ferramenta fundamental para a compreensão de alterações ambientais, considerando que as plantas formam o maior componente dos ecossistemas (Esteves, 2011). De acordo com Guarim Neto e Guarim (1996) trata-se de uma das ciências mais antigas, e estruturadas nas áreas das Ciências Biológicas, sendo um parâmetro norteador para diferentes temas e assuntos, onde os professores podem utilizar a abordagem interdisciplinar na condução de atividades inerentes ao processo de ensinar-aprender-vivenciar.

Diante do exposto, este artigo indica como os EFNs amazônicos podem ser utilizados no processo de ensino disseminando conhecimentos quanto aos componentes da flora e sua importância para o meio ambiente.

\section{Metodologia}

A pesquisa teve cunho qualitativo sendo realizada com alunos e professores pertencentes ao curso de Licenciatura de Ciências Biológicas, especificamente com as disciplinas de Fisiologia Vegetal e Morfologia dos Vegetais Superiores perfazendo um total de 21 alunos e 4 professores.

\section{Sondagem com professores e alunos}

Foi realizada a aplicação de questionários direcionados para alunos e professores. O questionário dos professores buscou a identificação das atividades desenvolvidas nos ENFs para trabalhar os conteúdos sobre a flora regional e sua importância para os ambientes. No questionário dos alunos verificou-se se há interação entre os conhecimentos botânicos com as questões ambientais e se estas informações são difundidas em ENFs.

\section{Intervenção: atividade nos ENFs}

Utilizaram-se dois espaços não formais: a) ASFRAMA (associação dos servidores da Suframa), localizada no km 60 da $\mathrm{Br}$ - 174 constituído por nascentes e com exemplares de briófitas, pteridófitas e liquens. b) Reserva Biológica da Campina/Campinarana, pertencente ao INPA (Instituto Nacional de Pesquisas da Amazônia), apresentando uma área de 900 ha, localizada no km 44 da Br-174 com tipo de formação vegetal arbustiva-arbórea-graminóide.

Os alunos durante a visita realizaram o registro com fotos e desenhos dos ambientes e observaram em cada área: importância da vegetação, principais habitats e suas variações de acordo com os ambientes; a dinâmica das relações entre vegetais, tipo de vegetação, ação antrópica nos locais 
visitados. Em cada ambiente foi sugerido observar mudanças na densidade das espécies, características morfológicas, densidade da serapilheira, presença de epífitas, briófitas, pteridófitas e liquens. Ao final das atividades foi realizado uma socialização com os alunos que participaram da atividade como forma de avaliar aspectos positivos a prática realizada nos ENFs. Após as atividades ENFs foi realizado uma atividade de verificação.

\section{Resultados e Discussão}

\section{Relato dos professores}

De acordo com as respostas dos professores entrevistados, percebeu-se que não há obrigatoriedade nas disciplinas que trabalham conteúdos botânicos de realizar uma correlação com as questões ambientais eminentes e, principalmente, de abordar conhecimentos botânicos em ENFs regionais. No entanto, os professores têm noção da responsabilidade em proporcionar aos alunos essas informações como mostra a Tabela 1, como meio de contribuir para a formação da concepção ambiental. Segundo ESTEVES (2011), qualquer que seja a definição de meio ambiente, até mesmo para um cidadão desprovido de conhecimento formal incluirá as plantas dentro deste contexto, no entanto, a maioria das pessoas não sabe como a botânica contribui para a manutenção do meio ambiente. Dentre os relatos obtidos dos professores, destacamos os contidos na Tabela 1.

Tabela 1: Relato dos professores quanto à importância da utilização dos ENFs para o ensino de botânica, bem como sua contribuição para a manutenção do meio ambiente.

\section{Cite três relevâncias ao se difundir esta temática em ENFs:}

"Contextualização, importância do conhecimento adquirido para preservação e uso racional dos recursos naturais da Amazônia; Correlação entre teorias e práticas de campo";

"Formação de uma concepção ambiental de acordo com a realidade local";

"Disseminação de conteúdos que possam promover noções de sustentabilidade adequada para o meio".

\section{Relato dos alunos sobre as atividades de ensino nos ENFs}

Em relação aos alunos percebe-se pelas respostas que há carência de informações em relação às riquezas sobre a flora e sua importância. $O$ conhecimento botânico é difundido sem a correlação dos EFNs amazônicos. Tais resultados podem estar associados ao fato das disciplinas serem desenvolvida de forma isolada, sem a interação das questões ambientais, e pela forma de abordagem principalmente teórica com atividades de práticas laboratoriais e pouca atividades nos ENFs regionais como evidencia a Figura 1.

revista brasileira 


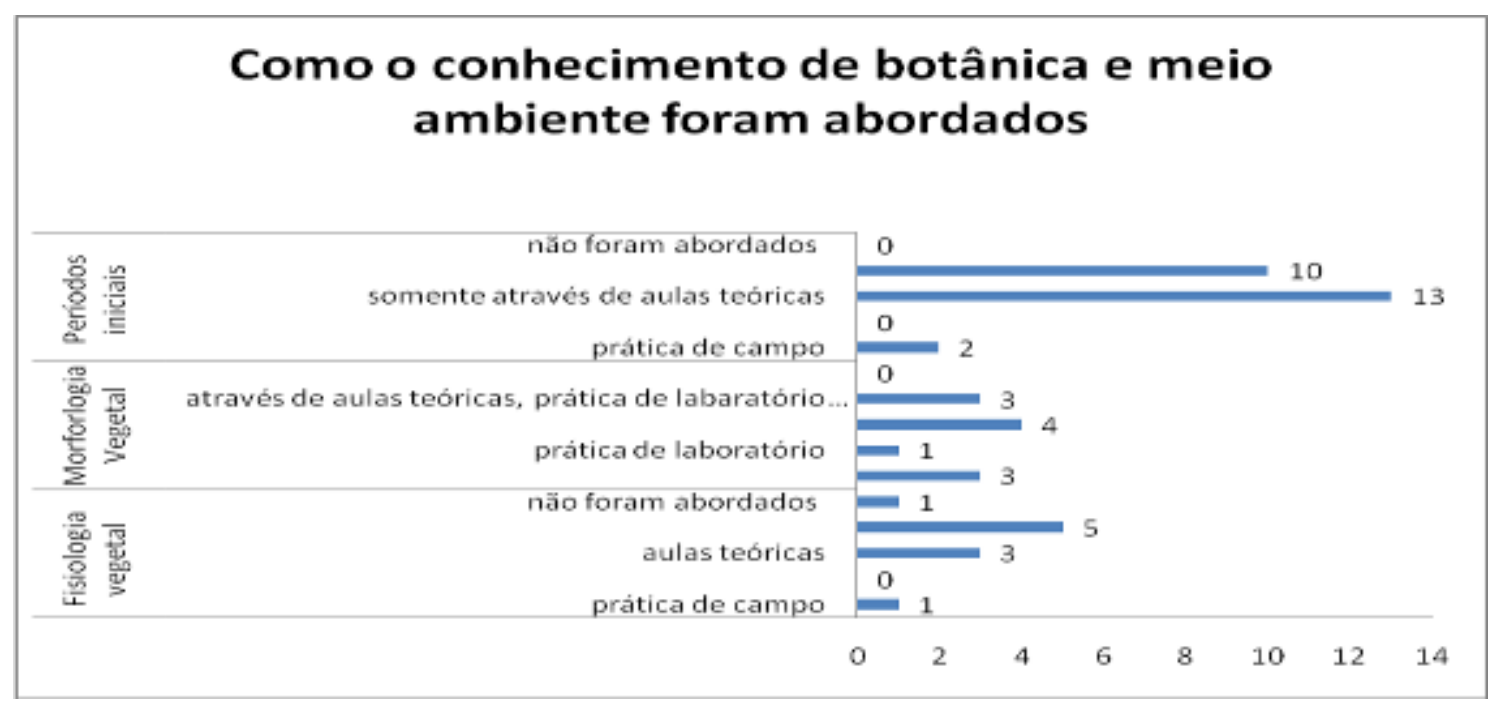

Figura 1: Informações dos alunos sobre a forma como os conteúdos de botânica e meio ambiente foram abordados nas disciplinas.

O fato da falta das inter-relações com as questões ambientais nos conteúdos e procedimentos didáticos revela que apesar de a EA ser exigida pela Constituição Federal de ser difundida, ainda não é aceita e executada conforme desejado, pois sugere ofensivas mobilizações para melhoria ambiental, sendo destacado que "quando bem realizada, a EA leva a mudanças de comportamento pessoal e a atitudes e valores de cidadania que podem ter importantes conseqüências sociais" (BRASIL, 2010, p.182).

Os alunos demonstraram por meio dos relatos (Tabela 2) e dos registros fotográficos (Figura 2) que compreenderam a importância da vegetação para a manutenção dos ecossistemas, bem como suas funções para o equilíbrio do meio ambiente. Segundo Ausubel (1982), o aprendizado de forma significativo somente acontece quando uma informação nova é adquirida mediante um esforço deliberado por parte do aprendiz em ligar a informação nova com conceitos ou proposições relevantes preexistentes em sua estrutura cognitiva.

Tabela 2: Relato e registro dos alunos durante as atividades nos ENFs . MV = Alunos de Morfologia Vegetal. ${ }^{* *} \mathrm{FV}=$ Alunos de Fisiologia Vegetal 
Percebe-se observações registradas pelos alunos que numa atividade nos ENFs pode-se compreender o papel dos elementos da floresta para a manutenção da vida e dos ecossistema. Desta forma práticas como estas podem repercutir em processos de mudanças de atitude em relação ao meios, pois segundo Kondrat e Maciel (2013) a EA sustenta uma recente discussão sobre as questões ambientais e transformações de conhecimentos, valores e atitudes que devem ser seguidos diante da nova realidade a ser construída, constituindo uma importante dimensão que necessita ser incluída no processo educacional constituindo práticas cotidianas dos educadores.

A partir das atividades desenvolvidas nos ENFs percebeu-se que há construção de conceitos por meio de confronto dos conhecimentos adquiridos em sala de aula frente às experiências vivenciadas nos ENFs. Observa-se na Figura 2, a riqueza da biodiversidade, registrado em imagens pelos alunos, apresentando um ambiente rico em briófitas (Figuras 2A e C) e pteridófitas (Figura 2B).
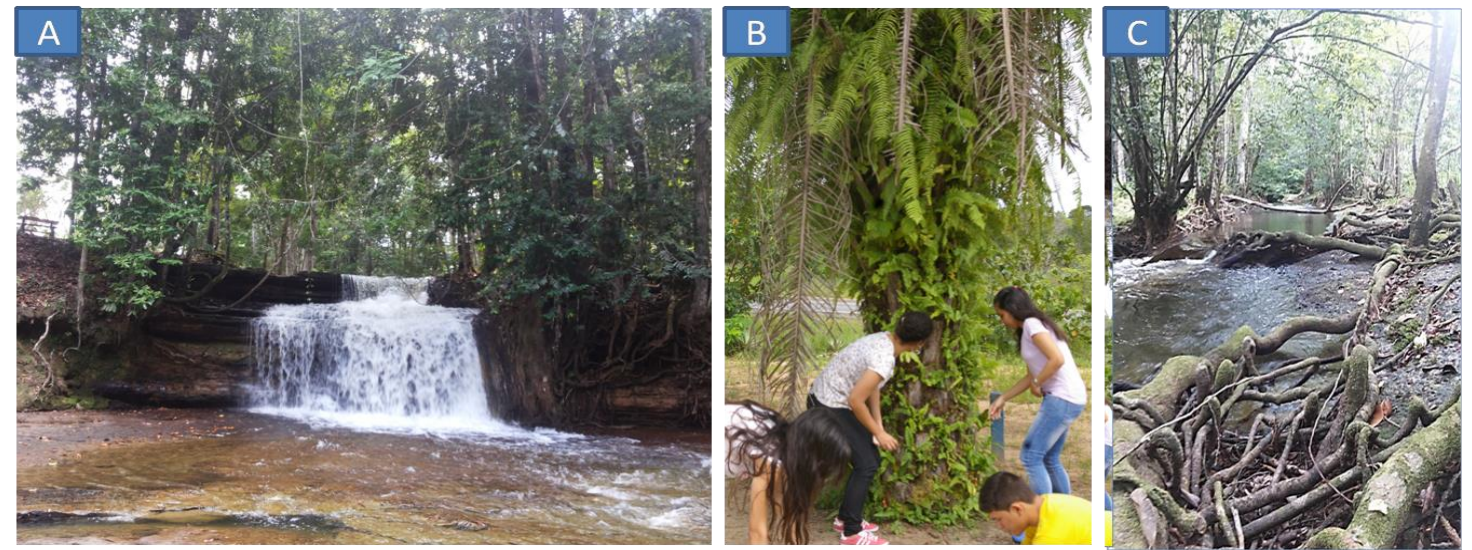

Figura 2: Atividades desenvolvidas nos ENFs da Cachoeira da Asframa Km 174 ManausPresidente Figueiredo. A: Cachoeira e vegetação. B: Pertidófitas. C: Corredeira e vegetação ciliar com briófitas

Conhecimentos repassados nas disciplinas de que trata do Estudo do $\mathrm{s}$ Vegetais Inferiores e intermediários que relata a conquista dos vegetais ao ambiente terrestre mostrando suas adaptações adquiridas e a participação dos mesmo como componentes do solo participando dos ciclos biogeoquímicos e servindo de alimento e abrigo para alguns invertebrados. Este tipo de atividade permite o confronto com estruturas observadas nos livros didáticos aos quais são apresentam aspectos diferenciados quando observados nos ambientes naturais. 
Os ENFs de Campina e Campinarana (Figura 3) permitiram a observação das especificidades em vegetação arbórea em diferentes portes (Figura 3B) e também as associações com liquens (Figura 3A e 3D) e epífitas (Figura $3 \mathrm{C}$ ). Esses exemplares botânicos descritos são encontrados nos livros do ensino médio, que muitas vezes são exemplificadas com exemplares de outras regiões, utilizando-se somente fotos e/ou figuras. Os alunos perceberam a importância da composição florística e a influência na manutenção dos ecossistemas representados nestes ENFs.
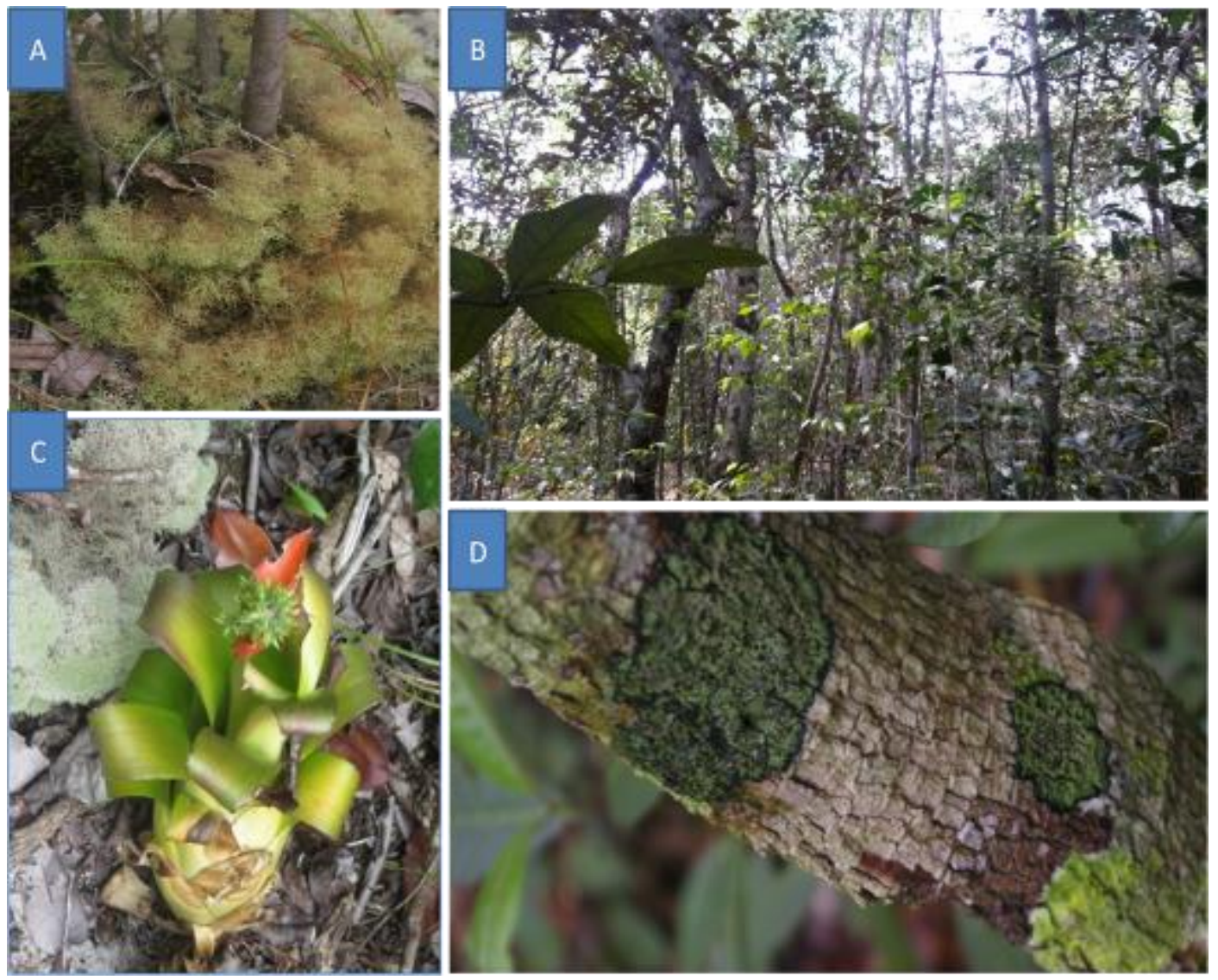

Figura 3: Atividades desenvolvidas nos ENFs na reserva de campina/campinarana do INPA. A: Liquens. B: Vegetação Geral. C: Bromélias epífitas. D: Liquens nos troncos

Segundo Araújo e Silva (2013), a diversidade biológica é uma característica específica da Amazônia. Sua floresta possui uma grande variedade de espécies nativas pouco estudadas e distribuídas principalmente em florestas de terra-firme, várzea e igapó. Essa diversidade florística e faunística constitui-se numa ferramenta potencial para subsidiar o ensino e aprendizagem em botânica. Sua imensa floresta nativa pode funcionar como um laboratório vivo para o desenvolvimento de atividades de ensino e de pesquisa. Os elementos bióticos como as árvores, os animais, os fungos e os elementos abióticos como a água presente nos rios, lagos e no solo podem constituir-se em recursos pedagógicos para o ensino de Ciências e Biologia. 
O uso de alternativas metodológicas de ensino em ENFs em especial, as reservas florestais amazônicas podem contribuir para que os professores de Biologia possam dar sentido ao conteúdo específico de Botânica e integrá-los às demais disciplinas do currículo escolar (ARAÚJO, 2009). Segundo as DCNEM (Brasil, 1998), a contextualização do ensino de ciências naturais é a forma pela qual o professor pode dar sentido ao conteúdo específico de sua área e integrá-lo às demais disciplinas do currículo escolar. Nesse sentido, o presente trabalho teve o objetivo de analisar potencialidades para promover aprendizagem significativa de Botânica.

A relevância do repasse dos conhecimentos de Botânica nas escolas de modo geral, se configura uma importante estratégia para a concretização de saberes relacionado à floresta e seus ecossistemas, que consequentemente proporcionará aos discentes a formação da concepção ambiental de maneira mais responsável e participativa, configurando um ensino mais motivador e gerador de sujeitos críticos e participativos.

Essa perspectiva do ensino de Ciências para o contexto amazônico viabiliza o alcance do objetivo dos PCN's de "valorizar a vida em sua diversidade e a preservação dos ambientes" (BRASIL, 1999, p. 86).

Assim, é uma necessidade a adoção de uma concepção de ensino de botânica que valorize a interação no processo ensino-aprendizagem, como forma de valorizar a compreensão do papel de cada integrante na manutenção da qualidade ambiental, e, consequentemente, na qualidade de vida. $O$ relato dos alunos quanto ao aprendizado em relação à importância da prática nos ENFs é apresentado na Tabela 3.

Tabela 3: Relato dos alunos quanto ao aprendizado em relação à importância da pratica nos ENFs. ${ }^{*} \mathrm{MV}=$ Alunos de Morfologia Vegetal ; ${ }^{* *} \mathrm{FV}=$ Alunos de Fisiologia Vegetal.

*MV "Os ganhos foram muito positivos, pois quando o ambiente é alterado pelo homem gera efeitos irreparáveis, porque tudo que está em harmonia não pode ser alterado".

*MV "OI cenário da Amazônia influencia numa porcentagem nas mudanças climáticas e no mundo isso não é somente nosso".

** FV "Como tudo está interligado, constituindo um ecossistema a destruição de alguns desses elementos como (solo, flora, água, etc.) afeta profundamente o ambiente"

FV "O aprendizado da morfologia, função e descrição dos vegetais garantem para nós o real significado e importância da preservação de todas as espécies para a manutenção ambiental, onde esse ecossistema preservado de ações antrópicas terá um sentido global"

Os alunos identificaram a diversidade de fatores bióticos e abióticos e a interação na composição dos ambientes (Figura 3A-D). Segundo Cunha (2009) as aulas nos ENFs favorecem a observação e a problematização dos fenômenos de uma forma mais concreta. Partindo da necessidade de 
ressignificar o processo ensino-aprendizagem, os ENFs despontam como lugares passíveis de desenvolvimento de aulas com metodologias que possibilitem 0 envolvimento dos estudantes em práticas educativas por viabilizarem um conhecimento articulado e sem fragmentações (SENICIATO e CAVASSAN, 2004).

\section{Atividade de verificação}

Realizou-se em sala de aula por meio da socialização das informações obtidas nas atividades desenvolvidas nos ENFs sendo investigado a compreensão dos conhecimentos botânicos para se compreender a participação da flora na composição e manutenção do meio ambiente. Pode-se observar que os discentes ao longo da atividade descreveram os ambientes e correlacionaram a importância da flora de uma forma global indicando sua participação nos ciclos e sua diversidade em função da plasticidade de cada espécie (Figura 4).
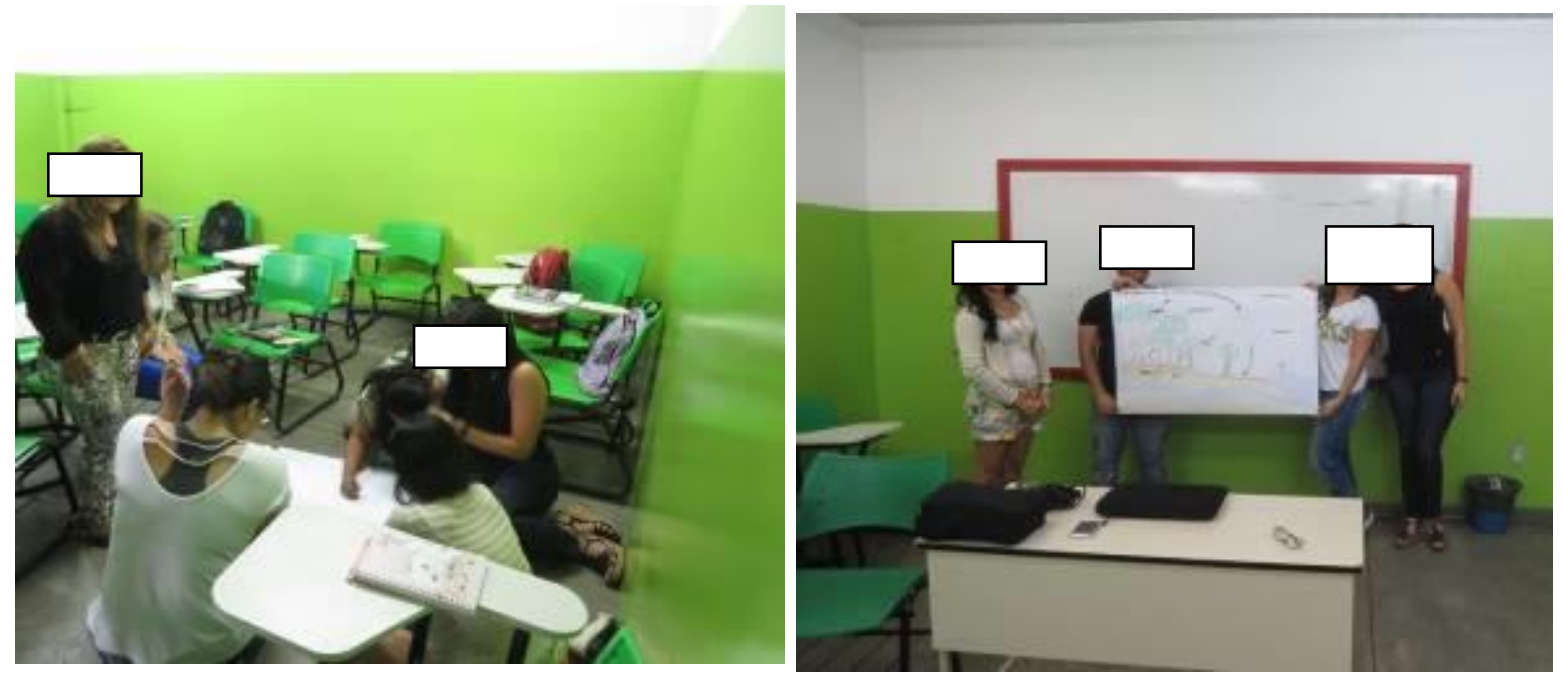

Figura 4: Socialização das informações obtidas nas atividades desenvolvidas nos ENFs.

\section{Considerações}

A pesquisa indicou que os conhecimentos botânicos podem ser mais compreendidos quando desenvolvidos em ENFs, sendo possível desmistificar a botânica como de difícil compreensão. No mesmo sentido, a utilização desses espaços motiva e aguça a curiosidade dos alunos, fortalecendo os conhecimentos teóricos. Foi possível enfatizar questões ambientais quanto à biodiversidade de espécies da flora regional, valorizando a importância dos vegetais para a manutenção dos ambientes. O trabalho promoveu um olhar diferenciado em relação às riquezas em flora regional permitindo compreender as interações existentes nestes ambientes. 


\section{Referências}

ARAÚJO, J.N.; SILVA, C.C.; TERÁN, A.F. A Floresta Amazônica. Um Espaço Não Formal em Potencial para o Ensino de Ciências. Anais do VIII ENPEC. 2011.

ARAÚJO, J.N.; SILVA, M.F.V. Floresta amazônica: espaço não-formal potencial para aprender botânica. Anais do XI CONGRESSO NACIONAL DE EDUCAÇÃO, 2013.

AUSUBEL, D.P. A aprendizagem significativa: a teoria de David Ausubel. São Paulo: Moraes, 1982.

BRASIL. Ministério da Educação e do Desporto. Secretaria de Educação Média e Tecnológica. Parâmetros Curriculares Nacionais: ensino médio. Brasília: Ministério da Educação, 1999.

CUNHA, A. M. O. Ensino de Ecologia em espaços não formais. III CLAE e IXCEB, 10 a 17 de Setembro de 2009. Anais.... São Lourenço, MG

DIAS, G.F. Educação Ambiental: princípios e práticas. 9 ed. São Paulo: Editora Gaia Ltda, 2008.

ESTEVES, L.M. Meio ambiente \& Botânica; Coordenação José de Ávila Aguiar Coimbra - São Paulo: Editora SENAC São Paulo, 2011.

GONÇALVES, E.G.; LORENZI, H. Morfologia Vegetal: organografia e dicionário ilustrado de morfologia de plantas vasculares. Instituto Plantarum de Estudos da Flora, São Paulo, 2008.

GUARIM NETO, G.; GUARIM, V.L.M.S. Atividades Interdisciplinares em Botânica. Revista de Educação Pública UFMT, 1996. Disponível em $<$ http://www.ufmt.br/revista/edicoes anteriores.htm> Acesso em 25 de abril de 2015.

KINOSHITA, L.S.; TORRES, R.B.; TAMASHIRO, J.Y; FORNI-MARTINS, E.R. (orgs) A botânica no ensino básico: Relatos de uma experiência transformadora. São Carlos. RiMa. 2006. 162p.

KONDRAT, H.; MACIEL, M.L. Educação ambiental para a escola básica: contribuições para o desenvolvimento da cidadania e da sustentabilidade. Revista Brasileira de Educação v. 18 n. 55 out.-dez. 2013

PINTO T.V.; MARTINS, I.M.; JOAQUIM, W.M. A construção do conhecimento em botânica através do ensino experimental. Anais do XIII Encontro Latino Americano de Iniciação Científica e LX Encontro Latino Americano de PósGraduação-Universidade do Vale do Paraíba, São José dos Campos, 2009.

SECCO, M.F.F.V.; SANTOS, J.B. (Coord.). Guia do educador. Belém: Museu Paraense Emílio Goeldi, 2008. 26p.

SENICIATO,T.; CAVASSAN, O. Aulas de Campo em ambientes naturais e aprendizagens em Ciências: um estudo com alunos do Ensino fundamental. Ciência e Educação, v.10,n.1,p.133-147, 2004. 